\title{
Marie Antoinette Mélières and Chloé Marèchal: Climate Change-Past, Present and Future
}

\author{
Eward R. Adlard ${ }^{1}$
}

(C) Springer-Verlag Berlin Heidelberg 2015

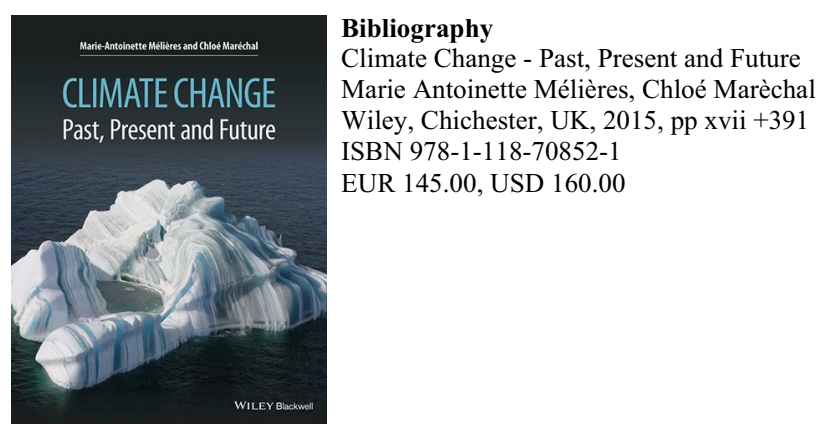

To describe this book as being like a wolf in sheep's clothing might seem rather odd but I think it justified in this instance. At first sight this volume could be taken as a typical "coffee table book" with all the features implicit in that pejorative description. The book is A4 in size; it makes use of several fonts and typefaces and contains a large number of figures, graphs and diagrams in all the colours of the rainbow.

In spite of its appearance, this book is a scholarly work on climatology that requires a good knowledge of physics (Coriolis force, heat transfer, Stefan's law), geology (the various glacial and interglacial epochs) and chemistry (the significance of oxygen isotope ratios), among others. I must admit that on a number of occasions I felt out of my depth in the subject matter especially as the authors seem to assume their readers' knowledge on many topics which receive no in-depth explanations. To take a trite example, I wonder how many readers would understand the nature and origin of the Coriolis force? There is also no explanation as to how oxygen isotope ratios are measured. These omissions are not surprising - the book is already nearly 400 large pages in length and such explanations would double its size (and cost!). At one point I thought that the volume should be entitled "a textbook of meteorology" but, as the authors themselves point out, the time scales involved are vastly different. In climatology the shortest time scale is the 11-year solar sunspot cycle, but most of the cycles discussed are in the order of thousands or millions of years. In spite of being aware of the basic facts of the greenhouse effect, I was not aware until I read this book just how complex it was and how a number of competing mechanisms were involved.

The book is an English translation of the original French and, apart from a few infelicities such as "sensible" heat which I think means "direct" heat, the translation is good.

There are several things I did not like such as the A4 size which meant that the book could only be read comfortably when sitting at a desk or table and when on Chapter 18 it was inconvenient to be referred to Figure 5.2. There was such a profusion of figures that I found some of them a distraction rather than a help. The contents are more "Present, Past and Future" rather than the title "Past, Present and Future".

In spite of these minor criticisms this is a beautifully produced book which is a must for anyone interested in climatology but the reader must be prepared for some hard work - this is certainly no coffee table book!
Eward R. Adlard

e.adlard77@btinternet.com

1 Burton, South Wirral, UK 